\title{
Tuberculosis among aboriginal and nonaboriginal persons in British Columbia
}

\author{
$L_{\text {Wang } M B^{1}}{ }^{1}$ K Noertjojo MB MSc ${ }^{2}$, RK Elwood MB MRCPI FRCPC ${ }^{1,2}$, \\ J Mark FitzGerald MD FRCPI FRCPC ${ }^{1,2}$ \\ ${ }^{1}$ British Columbia Centre for Disease Control Society, Ministry of Health, \\ Division of Tuberculosis, Vancouver, British Columbia; ${ }^{2}$ Department of Medicine, \\ University of British Columbia, Vancouver, British Columbia
}

\begin{abstract}
L Wang, K Noertjojo, RK Elwood, JM FitzGerald. Tuberculosis among aboriginal and nonaboriginal persons in British Columbia. Can Respir J 2000;7(2):151-157.
\end{abstract}

OBJECTIVE: To compare cases of tuberculosis (TB) diagnosed among aboriginal persons with a random sample of nonaboriginal persons diagnosed with $\mathrm{TB}$, and evaluate the trends in rates of disease between both groups during the same period.

DESIGN: A case-control study.

SETTING: A provincial TB control program.

PATIENTS AND METHODS: All patients with TB diagnosed among aboriginal persons in British Columbia between 1992 and 1996 were compared with control patients diagnosed during the same period. For each patient a control patient was identified.

INTERVENTION: The demographic details, type of disease, bacteriology, risk factors for TB, therapy received as well as mode of administration were documented. The number of contacts identified for each patient as well as the number of patients completing chemoprophylaxis were identified. The rates of disease during the same period were also documented.

RESULTS: During the study, 202 patients with TB were diagnosed among aboriginal persons and 201 controls were chosen. Apart from age at diagnosis $(35.1 \pm 20$ years versus
45.7 \pm 19.7 ), differences in the prevalence of lymphadenopathy $(5.9 \%$ versus $16.4 \%, \mathrm{P}=0.0008)$ and pleural disease ( $21.3 \%$ versus $16.4 \%, \mathrm{P}=0.00008)$, there were no differences in presentation between aboriginal and nonaboriginal people. Aboriginal people were more likely to have a history of contact with a patient with TB (53\% versus $17.9 \%, \mathrm{P}<0.05)$, to have received directly observed therapy (55\% versus $33.8 \%$, $\mathrm{P}=0.00002)$ and to have contacts who were purified protein derivative (PPD) positive $(4 \pm 9$ versus $2 \pm 3, \mathrm{P}=0.002)$. These contacts were more likely to start isoniazid $(2 \pm 3$ versus $1 \pm 1$, $\mathrm{P}=0.002)$. Overall, there was a significant decline in rates of TB among aboriginal persons compared with the general population, but there was a small increase in rates among all subjects in the final year of the study.

CONCLUSIONS: In the present study, significant variations in rates of TB among different population groups in British Columbia were found. During the study period, there was a greater decline in the rates of TB among aboriginal persons. A greater use of directly observed therapy and greater use of chemoprophylaxis occurred among aboriginal persons, which may have contributed to this decline, or alternatively, it simply reflects the natural evolution of the TB epidemic.

Key Words: Aboriginal persons; Epidemiology; Management; Tuberculosis

voir page suivante

Correspondence: Dr J Mark FitzGerald, British Columbia Centre for Disease Control Society, Division of Tuberculosis Control, 655 West 12th Avenue, Vancouver, British Columbia V5Z 4R4. Telephone 604-660-6127, fax 604-660-1950,

e-mailmarkf@interchange.ubc.ca 


\section{La tuberculose chez les personnes aborigènes et non aborigènes de la Colombie-Britannique}

OBJECTIF : Comparer les cas de tuberculose (TB) diagnostiqués chez les personnes aborigènes avec un échantillon aléatoire de personnes non aborigènes diagnostiquées avec une TB, et évaluer les tendances des taux de la maladie entre les deux groupes pendant la même période.

MODĖLE : Étude cas/témoins.

CONTEXTE : Programme provincial de contrôle de la TB.

PATIENTS ET METHODES : Tous les patients atteints de

TB diagnostiquée chez des aborigènes de la ColombieBritannique entre 1992 et 1996 ont été comparés avec des patients témoins diagnostiqués pendant la même période. Pour chacun des patients, on a identifié un patient témoin.

INTERVENTION : On a documenté les données démographiques, le type de la maladie, les données bactériologiques, les facteurs de risque pour la tuberculose, le traitement reçu ainsi que son mode d'administration. On a également identifié le nombre des contacts pour chaque patient de même que le nombre de patients ayant achevé leur chimioprophylaxie. On a aussi documenté les taux de maladie pendant la même période.

RÉSULTATS : Pendant l'étude, on a diagnostiqué 202 patients avec une TB chez des personnes aborigènes et on a choisi 201 témoins. À l'exception de l'âge au moment du diagnostic $(35,1 \pm 20$ ans par rapport à 45,7 $\pm 19,7)$, de différences dans la prévalence d'une lymphadénopathie $(5,9 \%$ par rapport à $16,4 \%, \mathrm{P}=0,0008)$ et d'une atteinte pleurale $(21,3$ $\%$ par rapport à $16,4 \%, \mathrm{P}=0,00008)$, il n'y avait aucune différence dans le tableau clinique entre les personnes aborigènes et non aborigènes. Il était plus probable que les personnes aborigènes avaient été en contact avec la tuberculose $(53 \%$ par rapport à $17,9 \%, \mathrm{P}<0,05)$, qu'elles avaient suivi une thérapie sous observation directe $(55 \%$ par rapport à 33,8 \%, $\mathrm{P}=0,00002$ ) et qu'elles avaient eu des contacts avec des sujets tuberculo-positifs $(4 \pm 9$ par rapport à $2 \pm 3, \mathrm{P}=0,002)$. Il était plus probable que ces contacts avaient débuté un traitement avec de l'isoniazide $(2 \pm 3$ par rapport à $1 \pm 1, \mathrm{P}=0,002)$, Globalement, on a observé une diminution significative des taux de TB parmi les personnes aborigènes comparativement à la population générale tandis qu'on a noté une légère augmentation des taux de TB chez tous les sujets dans la dernière année de l'étude.

CONCLUSIONS : La présente étude a révélé des variations significatives dans les taux de TB parmi différents groupes de population de la Colombie-Britannique. Pendant la période de l'étude, on a observé une plus grande diminution des taux de TB chez les personnes aborigènes. La thérapie sous observation directe et la chimioprophylaxie ont été plus utilisées chez les personnes aborigènes ce qui pourrait avoir contribué à cette diminution, ou bien, ce qui reflète simplement une évolution naturelle de l'épidémie de tuberculose.
$\mathrm{R}$ ates of tuberculosis (TB) in Canada, after declining for many years (1), plateaued in the late 1980s (2) and have only recently begun to fall slightly again (3). Historically, rates of TB among aboriginal Canadians have been significantly higher than those among the general population (4). Globally, TB is a major cause of morbidity and mortality (5), particularly in developing countries where the rates of the disease have been increasing, especially in areas where there is significant coinfection with HIV (6).

In British Columbia, as in other regions, the rates of TB among aboriginal Canadians have traditionally been much higher than in the general population. Because of this, we have attempted to treat all cases of active TB among aboriginal persons with directly observed therapy (DOT) and to use chemoprophylaxis more extensively among TB-infected aboriginal persons in British Columbia. During the study period, the rates of TB have declined significantly (7) while the rates of TB among the general population have remained static or increased slightly. We decided, therefore, to review the characteristics of aboriginal TB patients, both on and off reserves, and compare them with a random sample of nonaboriginal patients.

\section{PATIENTS AND METHODS}

In British Columbia, all cases of TB are reported to the Division of Tuberculosis at the British Columbia Centre for Disease Control in Vancouver. Both the provincial laboratory for the province and the pharmacy for dispensing TB drugs throughout the province are located in this division. In British Columbia, the Aboriginal TB Control Program is run as a separate unit within the larger provincial program. When diagnosed, patients are classified as aboriginal on reserve, aboriginal off reserve, Canadian nonaboriginal and foreign born. For the present study, all cases of active TB that occurred among aboriginal Canadians from January 1992 to December 1996 were identified. For each case of TB diagnosed on and off reserves among aboriginal Canadians, a control patient diagnosed with TB in the same month was picked randomly from the TB registry. This registry contains information on all cases of TB diagnosed in BC. Data are collected in a systematic manner using standardized data sheets. Control subjects were selected randomly from nonaboriginal TB patients diagnosed the same month as the aboriginal patients. Information collected included age, sex, symptoms, whether patients were admitted to hospital, duration of hospitalization and site of disease, whether pulmonary or extrapulmonary, or if both sites were involved.

Extrapulmonary disease was classified as lymphadenopathy, pleural, bone and joint, abdominal or other. In addition, the method of diagnosis was outlined. These included smear and culture positivity, histology consistent with the diagnosis or if the diagnosis was based on clinical and radiological features characteristic of TB in which there was an appropriate response to therapy. Bacteriological information included the percentage of patients with a positive sputum smear, or bronchoalveolar lavage or other body fluids. In addition, sensitivity patterns to first-line drugs including isoniazid (INH), rifampin, pyrazinamide, ethambutol and streptomycin were evaluated.

The drug therapy prescribed to the patients was documented as either self-administered or directly observed for the complete treatment period. 
Historical information included whether there was a prior diagnosis of TB, a history of TB treatment, a contact history or known exposure, a prior tuberculin test or a prior positive tuberculin test. A history of bacille Calmette-Guerin (BCG) vaccination was identified as were risk factors for the reactivation of TB infection. The number of contacts identified per patient was documented. In addition, the percentage of patients considered to have a positive tuberculin test $(5 \mathrm{~mm}$ or greater in duration to 5TU purified protein derivative) was documented. The number of contacts initiating chemoprophylaxis was also identified. Rates of disease were based upon population data from Statistics Canada for the nonaboriginal population and the aboriginal off-reserve population. Aboriginal on-reserve data were based on population figures supplied by the Medical Services Branch, Health Canada, Ottawa, Ontario, responsible for health care for this population.

Statistical analysis: This analysis was performed with the SPSS PC for DOS version 4.0 (SPSS Inc, Chicago, Illinois) and SPSS for Windows version 6.1.3 (SPSS Inc) statistical software. $\chi^{2}$ analyses were performed on categorical variables, and a two-sided $t$-test and ANOVA were performed on continuous variables. A Bonferroni method of multiple comparison adjustment was used when necessary. $\mathrm{P}<0.05$ was adopted as the level of significance (8). The curve estimation procedure on SPSS for Windows was adopted to analyze trends for the rate of TB across time. Regression analysis was performed to identify differences between both groups.

\section{RESULTS}

During the study, the rates of disease declined significantly among aboriginal Canadians, both on and off reserves $(91 / 100,000$ to $27 / 100,000, \mathrm{P}<0.05)$. The decline in rates was most notable among on-reserve patients, with the rate falling from $112 / 100,000$ to $17 / 100,000$, while in off-reserve patients the rates declined from $71 / 100,000$ to $36 / 100,000$. The rates for nonaboriginal Canadian-born and foreign-born people remained essentially unchanged during much of this period but rose slightly between 1995 and 1996 (Figure 1). A

TABLE 1

Characteristics and demographics of both the aboriginal and nonaboriginal tuberculosis patients

\begin{tabular}{|c|c|c|c|c|c|}
\hline & \multicolumn{2}{|c|}{ Aboriginal } & \multicolumn{2}{|c|}{ Nonaboriginal } & \multirow[b]{2}{*}{$\mathbf{P}$} \\
\hline & Number & $\%$ & Number & $\%$ & \\
\hline Age at diagnosis (years) & $35.1 \pm 20.0$ & & $45.7 \pm 19.7$ & & $<0.001$ \\
\hline Female & 90 & 44.6 & 83 & 41.3 & \\
\hline \multicolumn{6}{|c|}{ Medical history (symptoms) } \\
\hline Cough & 68 & 33.7 & 75 & 37.3 & \\
\hline Nightsweats & 24 & 11.9 & 25 & 12.4 & \\
\hline Fever & 28 & 13.9 & 31 & 15.4 & \\
\hline Other & 44 & 21.8 & 39 & 19.4 & \\
\hline Admitted to hospital & 78 & 38.6 & 64 & 31.8 & \\
\hline
\end{tabular}

total of 202 cases of TB were diagnosed among aboriginal persons and 201 control subjects were chosen from cases of TB diagnosed among Canadian nonaboriginal and foreignborn patients. The characteristics and demographics of both aboriginal and nonaboriginal patients are shown in Table 1. Aboriginal patients were more likely to be younger ( $35.1 \pm 20.0$ versus $45 \pm 19.7$ years of age, $\mathrm{P}<0.001)$. Patients' symptoms as well as number of subjects admitted to hospital did not differ between the groups. In Table 2, the type of disease and bacteriological results are shown. Nonaboriginal patients were more likely to have disease of the lymph nodes ( $14.4 \%$ versus $5.9 \%, \mathrm{P}=0.001)$ and less likely to have pleural disease $(7.5 \%$ versus $21.3 \%, \mathrm{P}=0.001)$. There was no difference in the proportion of patients with culture-proven disease. A history of TB of either diagnosis or treatment and predisposing factors, if any, are shown in Table 3. Aboriginal persons were more likely to have a contact history (53\% versus $17.9 \%, \mathrm{P}<0.001)$, a prior tuberculin skin test $(75.7 \%$ versus $54.7 \%, \mathrm{P}<0.001$ ), a prior positive tuberculin skin test $(65.8 \%$ versus $46.3 \%, \mathrm{P}<0.001)$ and $\mathrm{BCG}$ vaccination (25.2\% versus $10.9 \%, \mathrm{P}<0.001)$. Aboriginal persons were more likely to report a history of significant alcohol intake

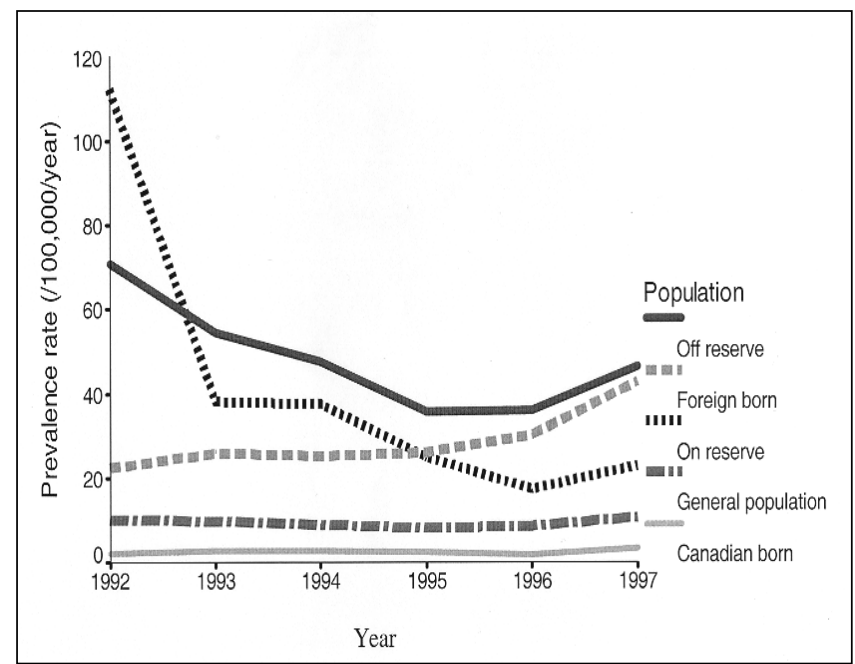

Figure 1) Rates of disease per 100,000 people among the different study groups between 1992 and 1996 
TABLE 2

Type of disease and bacteriological results in the aboriginal and nonaboriginal groups

\begin{tabular}{|c|c|c|c|c|c|}
\hline & \multicolumn{2}{|c|}{ Aboriginal } & \multicolumn{2}{|c|}{ Nonaboriginal } & \multirow[b]{2}{*}{$\mathbf{P}$} \\
\hline & Number & $\%$ & Number & $\%$ & \\
\hline Pulmonary tuberculosis & 130 & 64.4 & 132 & 65.7 & \\
\hline \multicolumn{6}{|l|}{ If extrapulmonary tuberculosis } \\
\hline Lymph nodes & 12 & 5.9 & 33 & 16.4 & 0.001 \\
\hline Pleural & 43 & 21.3 & 15 & 7.5 & 0.001 \\
\hline Abdominal & 4 & 2.0 & 1 & 0.5 & - \\
\hline Both & 35 & 17.3 & 8 & 4.0 & \\
\hline Smear positive & 80 & 39.6 & 81 & 40.3 & \\
\hline Culture positive & 145 & 71.8 & 157 & 78.1 & \\
\hline Clinical or pathological diagnosis & 57 & 28.6 & 52 & 20.8 & \\
\hline
\end{tabular}

TABLE 3

Tuberculosis history and predisposing factors

\begin{tabular}{|c|c|c|c|c|c|}
\hline & \multicolumn{2}{|c|}{ Aboriginal } & \multicolumn{2}{|c|}{ Nonaboriginal } & \multirow[b]{2}{*}{$\mathbf{P}$} \\
\hline & Number & $\%$ & Number & $\%$ & \\
\hline Prior tuberculosis diagnosis & 12 & 5.9 & 29 & 14.4 & - \\
\hline Prior tuberculosis treatment & 10 & 5.0 & 20 & 10.0 & - \\
\hline Prior contact/known exposure & 107 & 53.0 & 36 & 17.9 & $<0.001$ \\
\hline Prior tuberculin test & 153 & 75.7 & 110 & 54.7 & $<0.001$ \\
\hline Positive tuberculin test & 133 & 65.8 & 93 & 46.3 & $<0.001$ \\
\hline Intravenous drug abuse & 14 & 6.9 & 13 & 6.5 & - \\
\hline HIV sero positive & 8 & 4.0 & 21 & 11.5 & 0.01 \\
\hline HIV risk patient & 4 & 2.0 & 3 & 1.5 & - \\
\hline Alcoholism & 54 & 26.7 & 24 & 11.9 & 0.001 \\
\hline Renal disease & 5 & 1.5 & 2 & 1.0 & - \\
\hline
\end{tabular}

${ }^{*}$ Others include patients prescribed corticosteroids or other immunosuppressive therapy, predisposing condition such as cancer and diabetes mellitus. BCG bacille Calmette-Guerin vaccination; HIV Human immunodeficiency virus

(26.7\% versus $11.9 \%, \mathrm{P}<0.001)$ but less likely to be $\mathrm{HIV}$ positive $(4.0 \%$ versus $11.5 \%, \mathrm{P}<0.01)$. The treatment administered, drug susceptibility, data on number of contacts and chemoprophylaxis administered are shown in Table 4. The results were most notable for the higher use of directly observed therapy (55\% versus $33.8 \%$ ) among aboriginal persons and the greater number of contacts per active patient taking INH $(\mathrm{P}=0.002)$. Logistical regression analyses using two models, integrating univariate variables that were significant, into two different models were carried out and these results are shown in Table 5. Aboriginal persons were more likely to be vaccinated with BCG (OR $1.9,95 \%$ CI $0.9,3.8$ ), have prior contact (OR 2.4, 95\% CI 1.4,4.2) and excessive alcohol intake (OR 2.7, 95\% CI 1.4,5.1). They were less likely to self-administer treatment (Odds ratio [OR] 0.35, 95\% CI $0.21,0.59$ ) or be treated with ethambutol (OR $0.4795 \%$ CI $0.26,0.88)$.

\section{DISCUSSION}

In the present paper, we have outlined the characteristics of TB cases that occur among aboriginal persons, both on and off reserves in British Columbia, and compared them with nonaboriginal Canadian-born and foreign-born subjects. Our primary interest was not to compare separately Canadian-born nonaboriginal and foreign-born patients with aboriginal patients. Although we did complete this analysis, the differences related primarily to the higher rate of lymphadenopathy, the greater likelihood of resistance and the greater use of ethambutol in foreign-born persons. There were 118 foreign-born and 90 Canadian-born people in the comparison group. It has been well documented that primary disease is more likely to occur among aboriginal Canadians (9) and that foreign-born people, especially from Asian countries, are more likely to have TB lymphadenopathy (10). These differences did not change over time and are unlikely to account for the decline in TB rates seen among the aboriginal group. Although there was an excess of TB cases in the early 1990s related to clustering on reserves, when we completed an analysis of trends, the significant differences in rates of decline persisted over the study period. Specifically, we compared rates from 1994 to 1996, and the statistically 
TABLE 4

Treatment administered, drug susceptibility and data on number of contacts and chemoprophylaxis administered to the aboriginal and nonaboriginal groups

\begin{tabular}{|c|c|c|c|c|c|}
\hline & \multicolumn{2}{|c|}{ Aboriginal } & \multicolumn{2}{|c|}{ Nonaboriginal } & \multirow[b]{2}{*}{$\mathbf{P}$} \\
\hline & Number & $\%$ & Number & $\%$ & \\
\hline Self administration $^{\dagger}$ & 84 & 41.6 & 126 & 62.7 & 0.001 \\
\hline Directly observed treatment $^{\dagger}$ & 111 & 55.0 & 68 & 33.8 & 0.001 \\
\hline \multicolumn{6}{|l|}{ Treatment (drug use) } \\
\hline $\mathrm{INH}$ & 193 & 95.5 & 195 & 97.0 & \\
\hline RIF & 193 & 95.5 & 194 & 96.5 & \\
\hline Ethambutol & 33 & 16.3 & 61 & 30.3 & 0.001 \\
\hline Streptomycin & 3 & 1.5 & 7 & 3.5 & \\
\hline Sensitive to all drugs & 138 & 68.3 & 129 & 64.2 & \\
\hline \multicolumn{6}{|l|}{ If not senstive, resistant to } \\
\hline INH & 4 & 2.0 & 16 & 8.0 & 0.006 \\
\hline Number of contacts & $18 \pm 36$ & & $14 \pm 55$ & & - \\
\hline Number of contacts with PPD (+) & $4 \pm 9$ & & $2 \pm 3$ & & 0.002 \\
\hline Number taking INH & $2 \pm 7$ & & $1 \pm 1$ & & 0.002 \\
\hline
\end{tabular}

INH Isoniazid; PPD Purified protein derivative; PZA pyrazinamide; RIF Rifampin. ${ }^{*}$ Fishers exact test used because of small numbers. ${ }^{\dagger}$ The total number treated is incomplete because of a small number of subjects in both groups who either did not initiate treatment or left the province

TABLE 5

Logistical regression analysis on the differences between aboriginal and nonaboriginal Canadian cases of tuberculosis

\begin{tabular}{|c|c|c|c|c|}
\hline \multirow[t]{2}{*}{ Independent variable } & \multicolumn{2}{|c|}{ Model one } & \multicolumn{2}{|c|}{ Model two } \\
\hline & OR & $95 \% \mathrm{Cl}$ & OR & $95 \% \mathrm{Cl}$ \\
\hline Age at diagnosis (years) & 0.98 & $0.97-0.99$ & 0.98 & 0.97-0.99 \\
\hline Prior contact (yes versus no) & 2.4 & $1.4-4.2$ & 2.3 & $1.3-4.0$ \\
\hline Prior tuberculin test (yes versus no) & 1.8 & $1.1-3.2$ & 1.7 & $0.9-2.9$ \\
\hline \multicolumn{5}{|l|}{ Risk factors } \\
\hline Alcoholism & 2.7 & $1.4-5.1$ & 2.8 & $1.1-4.1$ \\
\hline \multicolumn{5}{|l|}{ Extent of disease } \\
\hline Lymph nodes & 0.27 & $0.11-0.68$ & 0.27 & $0.11-0.68$ \\
\hline Pleural & 2.3 & $1.1-4.7$ & 2.2 & $1.1-4.6$ \\
\hline Treatment with ethambutol & 0.47 & $0.26-0.88$ & 0.49 & $0.26-0.90$ \\
\hline
\end{tabular}

BCG bacillus Calmette-Guerin; HIV human immunodeficiency virus; OR Odds ratio. Univariate variables that were significant have been integrated into the models

significant trend $(\mathrm{P}<0.024)$ persisted for both on-reserve and off-reserve patients. We identified no clustering off reserves nor an increase in the absolute number of cases among off-reserve subjects during the study period.

Interestingly, there was a much higher proportion of aboriginal persons who had a history of contact and a prior positive tuberculin test. These results indicate that further reductions in the rates of aboriginal TB could be achieved with even more aggressive use of chemoprophylaxis. Not surprisingly, a greater proportion of aboriginal persons had BCG vaccination, and this is consistent with the fact that BCG offers only partial protection against the development of TB and that this protection is time limited (11). Although the efficacy of BCG is controversial, it is unlikely to have affected the decline seen among aboriginal persons because the use of BCG did not change during the study period. 
In general, risk factors for TB were equivalent in both groups, with a notable exception of alcoholism occurring in over 25\% of aboriginal subjects compared with just under $12 \%$ among nonaboriginal persons $(\mathrm{P}<0.001)$. Interestingly, one would have anticipated that this would have adversely affected the efficacy of the control program, but this did not appear to be the case. Infection with HIV as a risk factor occurred more commonly among nonaboriginal persons, but a significant proportion of both aboriginal and nonaboriginal patients were known to be HIV positive. Also, a significant number of patients were from a group putting them at risk of being HIV positive (especially intravenous drug users) or had confirmed HIV as a risk factor for their TB. In all, 63 of the 403 patients studied (15.6\%) fell into these high risk groups. This increase is consistent with a change from previous (12) and more recent reports on HIV-related TB in British Columbia (13), outlining a greater tendency for AIDS- related TB to occur among intravenous drug users and aboriginal persons. This increase in the number of HIV-related TB cases over time highlights the need for targeted surveillance among those at risk of dual HIV-TB infection, especially aboriginal persons. We have also identified clustering of TB cases in these same groups (14).

Both groups were as likely to have bacteriologically proven disease, but there were significant differences in the resistance pattern between the groups studied, with the nonaboriginal persons much more likely to be resistant to isoniazid, rifampin or streptomycin. Multidrug resistant disease was not documented during the study period. Our data with regard to the risk of resistance are consistent with previous reports of resistance patterns in TB cases in western Canada (15), and reflect the impact on immigrants from high prevalence countries where drug resistance is a major problem. The pattern of resistance was unchanged during the study period and therefore is unlikely to account for the differences in rates of TB seen.

Recent attention has focused on the benefits of directly observed therapy versus self-administered therapy (16). A number of reports have been presented recommending the more widespread use of directly observed therapy $(17,18)$. There are limited data, however, to justify its use, although some have argued persuasively with regard to the financial benefits of this type of therapy delivery (18). A recent randomized, controlled trial study from South Africa showed no benefit from the use of directly observed therapy compared with self-administered therapy, but this study has been criticized because of the relatively small percentage of eligible subjects enrolled (19).

In the present study, we found significantly more aboriginal persons received directly observed therapy than did nonaboriginal persons. Given the equivalent characteristics of the patients at the time of presentation, greater use of directly observed therapy may be a factor that accounts for the decline in rates of TB among aboriginal persons both on and off reserves. Contact tracing among aboriginal persons was also more successful. Unfortunately, for the early part of the study, data regarding chemoprophylaxis offered were not coded for nonaboriginal persons. In addition to greater completion rates with directly observed therapy and greater assurance that the therapy has in fact been taken, we have shown recently greater efficacy in terms of completion of medication when directly observed chemoprophylaxis is used (20) among the aboriginal population. This greater surveillance may reflect the fact that aboriginal persons diagnosed with TB, particularly on reserves, live in relatively small communities, and because of the high risk of clustering in these populations (21), the entire communities may be surveyed. We have argued previously that, in high prevalence groups, there should be caution in initiating chemoprophylaxis (22) unless there is a satisfactory program in place to deliver therapy to patients with active cases of TB, especially those that are smear positive.

\section{CONCLUSIONS}

We have compared the presentation and management of TB among aboriginal and nonaboriginal persons in British Columbia. In the early part of this study, there was a significant reduction in rates of TB among aboriginal persons in British Columbia. It is unclear if the decline in rates of disease is primarily related to the greater use of directly observed therapy and chemoprophylaxis in the high risk population, or is part of the natural decline in rates expected at this stage of the epidemic among aboriginal persons. More recently, this decline has been reversed in all groups, including aboriginal persons, and indicates a need for continued vigilance and strategies to improve control in all groups. This cautionary note needs to be emphasized particularly for aboriginal persons, given the relatively high prevalence of $\mathrm{TB}$ infection in this population, and because recent epidemiological surveillance that we have undertaken indicates a disproportionately high HIV sero-prevalence among aboriginal intravenous drug users in Vancouver (23) compared with the nonaboriginal population. There is a significant risk that these encouraging results may not be sustained. The risk of dual HIV-TB infection is such that ongoing, targeted surveillance of this high risk population will need to persist if the currently reported declining rates of TB among aboriginal persons in British Columbia are to continue, and we are to avoid the documented rising rates of HIV-related TB reported from New York City and other large urban centres in the United States (24). Further studies, especially randomized, controlled trials with appropriate cost effectiveness analysis, are needed urgently to support our recommendations that directly observed therapy should be used on a more widespread basis. Such studies should also account for the significant gaps in knowledge about TB that patients have (25) and the added challenge of controlling TB in the inner city (26).

ACKNOWLEDGEMENTS: We acknowledge the assistance of Ms Jean Fraser and her staff of the TB registry. We also acknowledge the hard work of the many nurses and outreach workers who participate in the provincial TB program. We thank Ms Fay Hutton for helping with data collection and analysis. Dr Lai Wang was funded by the World Bank. 


\section{REFERENCES}

1. FitzGerald JM, Dy Buncio A, Branckner A. Recent trends in tuberculosis in Canada 1979-89. Am Rev Respir Dis 1993;147(Suppl 2). ( Abst A118)

2. Statistics Canada. Tuberculosis Statistics 1990. Ottawa: Statistics Canada, 1992.

3. Tuberculosis in Canada. Ottawa?: Health Canada, 1995.

4. Gaudette LA, Ellis E. Tuberculosis in Canada: a focal disease requiring distinct control strategies for different risk groups. Tuberc Lung Dis 1993;74:244-53.

5. Raviglionne M, Snider DE, Kochi A. Global epidemiology of tuberculosis: morbidity and mortality of a world wide epidemic. JAMA 1995;273:220-6.

6. Schulzer M, Radhamani M, Grzybowski S, FitzGerald JM. Methodologic issues in the development of a model of the interaction of HIV infection and tuberculosis infection. Int J Epidemiol 1994;23:40027.

7. Division of Tuberculosis Control. Statistical and Epidemiologic Report 1993-1995. Vancouver: Ministry of Health and Ministry Responsible for Seniors, 1996

8. Armitage P, Berry G. Statistical Methods in Medical Research, 2nd edn. Oxford: Blackwell Scientific Publications, 1987.

9. Enarson DA, Grzybowski S. Incidence of active tuberculosis in the native population of Canada. CMAJ 1986;134:1149.

10. Enarson DA. Active tuberculosis in Indochinese refugees in British Columbia. CMAJ 1984;131:39-42.

11. Colditz GA, Brewer TF, Berkley CS, et al. Efficacy of BCG vaccine in the prevention of tuberculosis: a meta-analysis. JAMA 1994;271:698702 .

12. Korzeniewska-Kosela M, FitzGerald JM, Vedal S, et al. The spectrum of tuberculosis in patients with HIV infection in BC: a report of 40 cases. CMAJ 1992;146:1927-34.

13. Blenkush M, Korzeniewska-Kosela M, Elwood RK, Black W, FitzGerald JM. HIV-related tuberculosis in British Columbia: indications of a rise and change in risk groups. Clin Invest Med 1996;19:271-8

14. Blenkush M, Kunimoto D, Black W, Elwood RK, FitzGerald JM.
Evidence for TB clustering in Vancouver: results from a pilot study using RFLP fingerprinting. Can Com Dis Rep 1996;22-7:49-51.15.

15. Long R, Fanning A, Cowie R, Hoeppner V, FitzGerald JM. Antituberculosis drug resistance in Western Canada. Can Respir J 1997;4:71-6.

16. Weis SE, Slocum P, Blais FX, et al. The effect of directly observed therapy on the rates of drug resistance and relapse in tuberculosis. N Engl J Med 1994;330:1179-84.

17. Morse D. Directly observed therapy for tuberculosis: spend now or pay later. Br Med J 1996;312:719-20. (Edit)

18. Iseman MD, Cohn DL, Sbarbaro JA. Directly observed treatment of tuberculosis: we cannot afford not to try it. N Engl J Med 1993;328:576-8.

19. Zwarenstein M, Schoeman JH, Vundule C, Lombard CJ, Tatley M. Randomized controlled trial of self-supervised and directly observed treatment of tuberculosis. Lancet 1998;353:1340-3.

20. Heal G, Elwood RK, FitzGerald JM. Acceptance and safety of directly observed versus self administered daily isoniazid preventive therapy in Aboriginal people in British Columbia. Int J Tuberc Lung Dis 1998;2;979-83.

21. FitzGerald JM, Black WA, Kunimoto D. Evaluation of non-HIV related drug sensitive cluster outbreaks of TB with PCR based DNA finger printing. Can Respir J 1996;3:317-21.

22. FitzGerald JM. Downside of isoniazid chemoprophylaxis. Lancet 1995;345:404

23. FitzGerald JM, Patrick D, Strathdee S, et al. Prevalence of tuberculosis infection in a population of intravenous drug users. Am J Respir Crit Care Med 1997;155 (Suppl 2). (Abst A561)

24. Brudney K, Dobkin J. Resurgent tuberculosis in New York City. Human immunodeficiency virus, homelessness, and the decline of tuberculosis control programs. Am Rev Respir Dis 1991;144:745-9.

25. Broder S, Elwood RK, FitzGerald JM. Knowledge, attitudes, and beliefs about tuberculosis in two different populations in British Columbia. Am J Respir Crit Care Med 1997;155 (Suppl 2). (Abstr A727)

26. FitzGerald JM. Optimizing tuberculosis control in the inner city. Editorial. CMAJ 1999;160:821-2. 


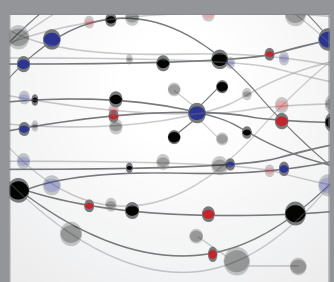

The Scientific World Journal
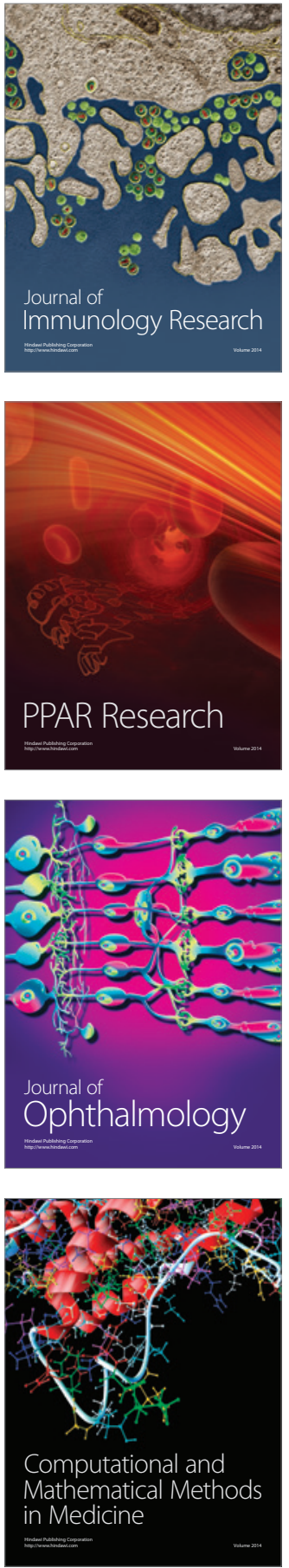

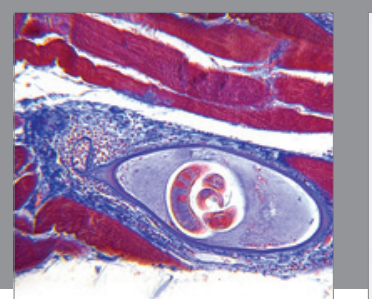

Gastroenterology Research and Practice

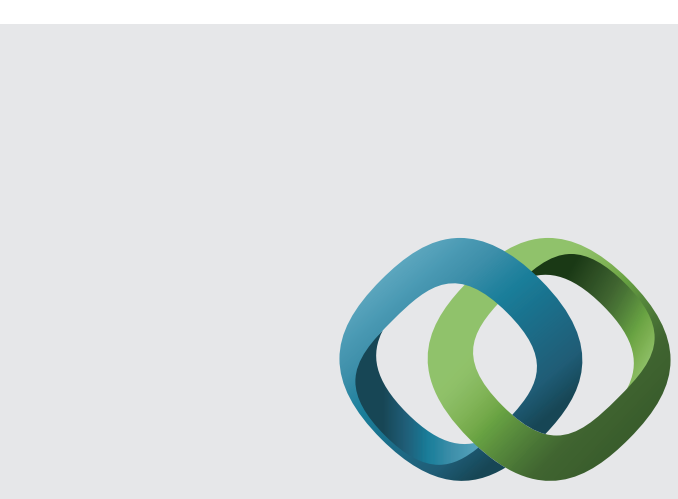

\section{Hindawi}

Submit your manuscripts at

http://www.hindawi.com
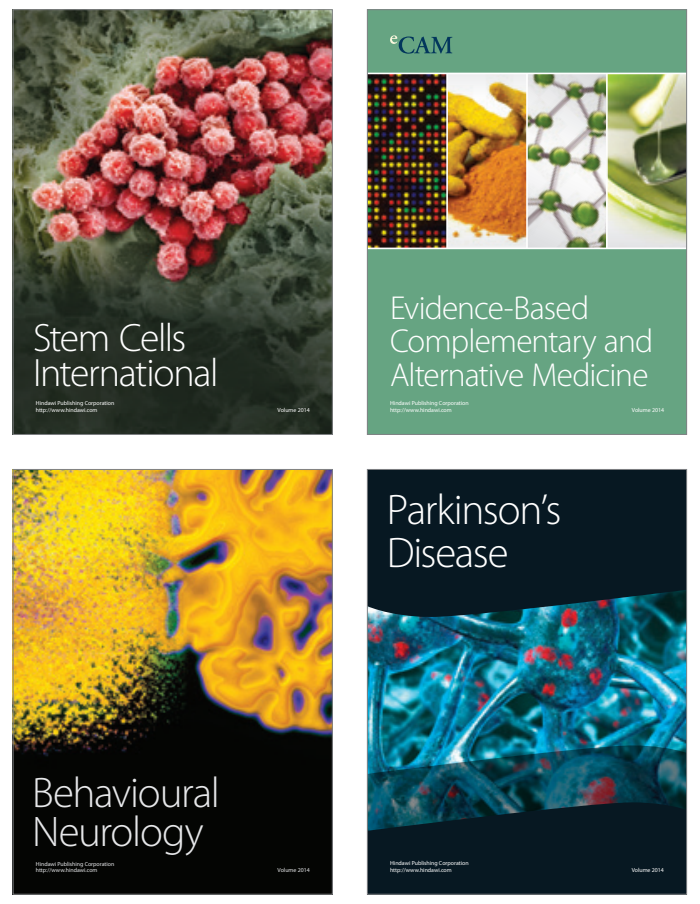
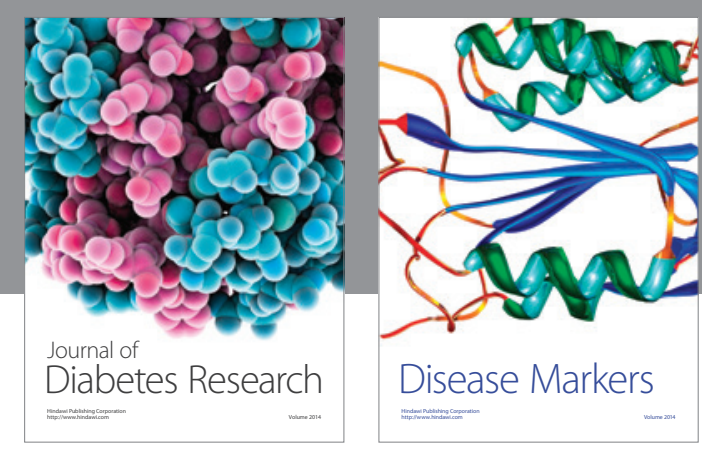

Disease Markers
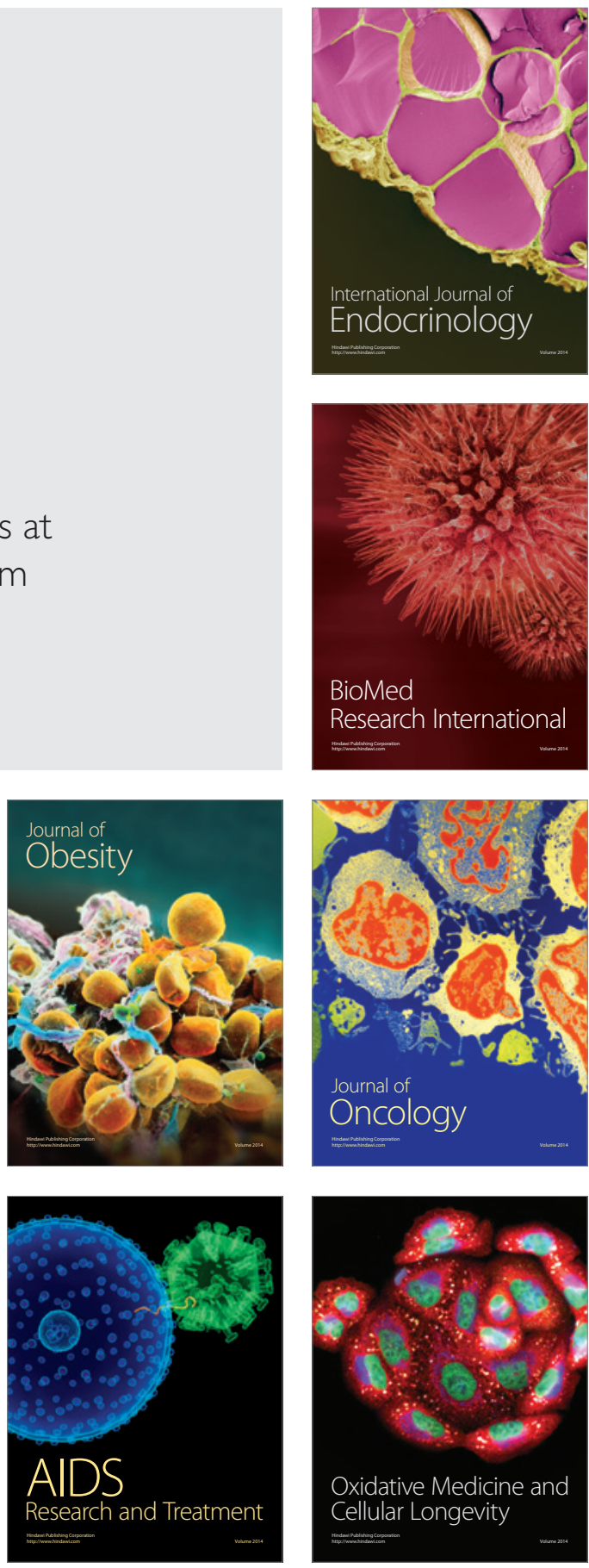